\title{
Correction to: Synthesis and evaluation of iridium(III) complexes on antineoplastic activity against human gastric carcinoma SGC-7901 cells
}

\author{
$\mathrm{Li} \mathrm{Tian}^{1} \cdot$ Yuanyuan Zhang ${ }^{1} \cdot$ Huiwen Zhang ${ }^{1} \cdot$ Yi Zhou $^{1} \cdot$ Wenlong $\mathrm{Li}^{1} \cdot$ Yuhan Yuan $^{1} \cdot$ Jing Hao $^{1} \cdot$ Linlin Yang $^{2}$. \\ Yunjun Liu ${ }^{1}$
}

Published online: 8 October 2021

(c) The Author(s), under exclusive licence to Society for Biological Inorganic Chemistry (SBIC) 2021

\section{Correction to: JBIC Journal of Biological Inorganic Chemistry (2021) 26:705-714 https://doi.org/10.1007/s00775-021-01895-3}

In the original article published, the email addresses of the corresponding authors are interchanged.

The correct email addresses are given below:

Linlin Yang: yanglinlin@gzhmu.edu.cn.

Yunjun Liu: lyjche@gdpu.edu.cn.
Publisher's Note Springer Nature remains neutral with regard to jurisdictional claims in published maps and institutional affiliations.

The original article can be found online at https://doi.org/10.1007/ s00775-021-01895-3.

Linlin Yang

yanglinlin@gzhmu.edu.cn

$\triangle$ Yunjun Liu

lyjche@gdpu.edu.cn

1 School of Pharmacy, Guangdong Pharmaceutical University, Guangzhou 510006, People's Republic of China

2 Department of Pediatrics, Guangdong Women and Children Hospital, Guangzhou 510010, People's Republic of China 